\title{
Molecular prognostic factors in small-intestinal neuroendocrine tumours
}

\author{
K G Samsom¹, L M van Veenendaal'2, G D Valk³ ${ }^{3}$ M R Vriens ${ }^{4}$, M E T Tesselaar ${ }^{2}$ and J G van den Berg ${ }^{1}$ \\ 'Department of Pathology, Netherlands Cancer Institute, Amsterdam, The Netherlands \\ 2Department of Medical Oncology, Netherlands Cancer Institute, Amsterdam, The Netherlands \\ ${ }^{3}$ Department of Endocrine Oncology, University Medical Centre Utrecht, Utrecht, The Netherlands \\ ${ }^{4}$ Department of Surgical Oncology and Endocrine Surgery, University Medical Centre Utrecht, Utrecht, The Netherlands \\ Correspondence should be addressed to G D Valk: G.D.Valk@umcutrecht.nI
}

\begin{abstract}
Background: Small-intestinal neuroendocrine tumours (SI-NETs) represent a heterogeneous group of rare tumours. In recent years, basic research in SI-NETs has attempted to unravel the molecular events underlying SI-NET tumorigenesis. Aim: We aim to provide an overview of the current literature regarding prognostic and predictive molecular factors in patients with SI-NETs.

Method: A PubMed search was conducted on (epi)genetic prognostic factors in SI-NETS from 2000 until 2019.

Results: The search yielded 1522 articles of which 20 reviews and 35 original studies were selected for further evaluation. SI-NETs are mutationally quiet tumours with a different genetic make-up compared to pancreatic NETs. Loss of heterozygosity at chromosome 18 is the most frequent genomic aberration (44-100\%) followed by mutations of CDKN1B in 8\%. Prognostic analyses were performed in 16 studies, of which 8 found a significant (epi)genetic association for survival or progression. Loss of heterozygosity at chromosome 18, gains of chromosome 4, 5, 7, 14 and 20p, copy gain of the $S R C$ gene and low expression of RASSF1A and P16 were associated with poorer survival. In comparison with genetic mutations, epigenetic alterations are significantly more common in SI-NETS and may represent more promising targets in the treatment of SI-NETs.

Conclusion: SI-NETs are mutationally silent tumours. No biomarkers have been identified yet that can easily be adopted into current clinical decision making. SI-NETs may represent a heterogeneous disease and larger international studies are warranted to translate molecular findings into precision oncology.
\end{abstract}

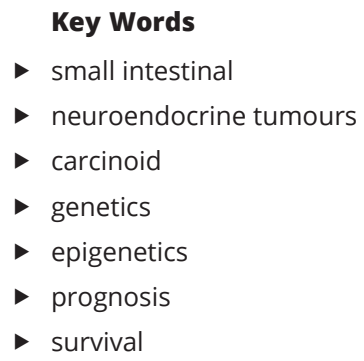

\section{Introduction}

Well-differentiated neuroendocrine tumours (NETs) represent a heterogeneous group of rare tumours, which have a relatively indolent disease course. Primary NETs can arise from neuroendocrine cells at various anatomic sites. They most commonly develop in the gastrointestinal tract and bronchopulmonary system $(1,2,3)$. NETs can be classified as functional or non-functional, based on whether they cause clinical symptoms as a result of hormone secretion or not. In patients with metastatic small-intestinal NETs (SI-NETs), the carcinoid syndrome is common, which is characterised by diarrhoea, episodic flushing, bronchospasm and often carcinoid heart disease leading to right valvular dysfunction (4). Patients with non-functional SI-NETs are often asymptomatic or experience non-specific symptoms resulting in metastatic disease at the time of diagnosis in $27-73 \%$ of patients $(1,2,3)$. In contrast to pancreatic NETs, SI-NETs are not known to arise in the context of hereditary syndromes,

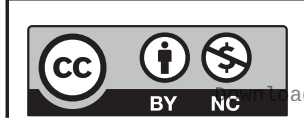


for example multiple endocrine neoplasia (MEN) type 1 or 2 and Von Hippel Lindau disease.

The reported incidence of SI-NETs has increased over the last four decades, from 0.2 per 100,000 individuals in 1973 to 1.25 per 100,000 individuals in 2012 (5). This progressive rise can mainly be contributed to more frequent use and improvements of diagnostic modalities or alterations in pathological disease definition $(2,5)$. In the group of gastroenteropancreatic NETs, SI-NETs are second most prevalent after rectum NETs and followed by pancreatic NETs (5). Moreover, SI-NETs are the most frequent cancer type of the small intestine (6).

Currently, treatment for patients with SI-NETs is based on the availability of several treatment modalities, for example, surgery, liver-directed therapies, somatostatin receptor analogues and peptide receptor radionuclide therapy rather than on precision medicine. In case of nonfunctional, advanced and progressive SI-NETs, everolimus, targeting the P13K/AKT/mTOR (mammalian target of rapamycin) pathway, has demonstrated anti-proliferative effects $(7,8,9)$. However, there is no biomarker available that predicts response to everolimus.

To conclude, personalised treatment based on molecular profiling has not yet entered the arena of treatment modalities in advanced SI-NETs.

In order to move towards precision medicine, the genomic landscape of SI-NETs has been under increasing investigation over the past years in the hope of unravelling the molecular events underlying NET tumorigenesis, facilitating the identification of novel therapeutic targets, rational (targeted) therapy management strategies and to improve prognosis. Recently, whole-genome sequencing of primary pancreatic NETs revealed several genomic events which characterise their pathogenesis and are associated with tumour progression (10). In general, gene expression-based subtyping has led to new classifications of multiple tumour types. In contrast, the genomic landscape of SI-NETs remains poorly elucidated and biomarkers have not yet been identified. Moreover, the genetic constitution of SI-NETs has been shown to differ compared to pancreatic NETs (11). With this review we aim to provide the clinician treating SI-NETs with an overview of the recent studies evaluating molecular characteristics of SI-NETs and their predictive and prognostic significance.

\section{Methods}

A literature search was performed in PubMed in March 2019. As our main objective was to provide an up to date overview of the current literature regarding prognostic molecular factors in SI-NETs for clinicians treating patients with SI-NETs, we did not aim to perform a formal systematic review. The domain of this search consisted of adult patients with sporadic SI-NETs, the determinant of genetic or epigenetic alterations and the outcomes of prognosis, survival or progression. Synonyms of SI-NETs and (epi)genetic alterations with the outcome described as prognosis, survival and progression were used for the search. Search terms and syntax are described in detail in Table 1. Screening based on title and abstract was conducted by one reviewer, in case of uncertainties a second reviewer was consulted. Citation search of the included articles was performed to identify additional original studies.

Inclusion criteria consisted of patient populations $>18$ years, human, full-text available in English, published between 01/01/2000 and 01/03/2019 and studies on gastroenteropancreatic NETs. Studies with a patient population with underlying genetic syndromes, no separate genome analysis for SI-NETs, using previously published results and on the taxonomy of SI-NETs were excluded.

\section{Results}

The PubMed search yielded 1522 hits, of which 1461 articles were excluded after screening of title and abstract (Fig. 1). Following the full-text screening of 61 articles,

Table 1 Search terms and syntax.

\begin{tabular}{|c|c|}
\hline & \\
\hline & $\begin{array}{l}\text { OR malignan*[Title/Abstract])) AND ((neuroendocrin*[Title/Abstract]) OR ((((((small[Title/Abstract] AND bowel[Title/ } \\
\text { Abstract])) OR ileal*[Title/Abstract]) OR jejun*[Title/Abstract]) OR duoden*[Title/Abstract]) OR midgut[Title/ } \\
\text { Abstract]))))) AND ((((((((((genom*[Title/Abstract]) OR epigenetic*[Title/Abstract]) OR gene*[Title/Abstract]) OR } \\
\text { exom*[Title/Abstract]) OR chromosom*[Title/Abstract]) OR molecular*[Title/Abstract]) OR allel*[Title/Abstract])) OR } \\
\text { sequenc*[Title/Abstract]) OR (((((methylation*[Title/Abstract]) OR mutation*[Title/Abstract]) OR alteration*[Title/ } \\
\text { Abstract]) OR amplificat*[Title/Abstract]) OR loss[Title/Abstract])))) AND (((prognos*[Title/Abstract]) OR } \\
\text { survival*[Title/Abstract]) OR progressi*[Title/Abstract])) }\end{array}$ \\
\hline $\begin{array}{l}\text { earch } \\
\text { terms }\end{array}$ & 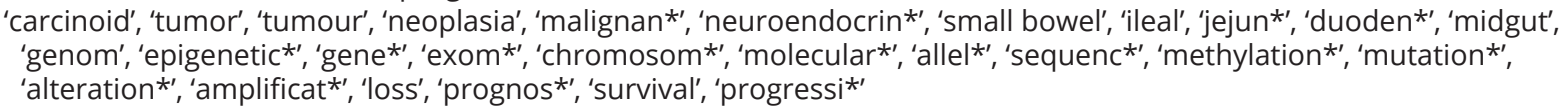 \\
\hline
\end{tabular}




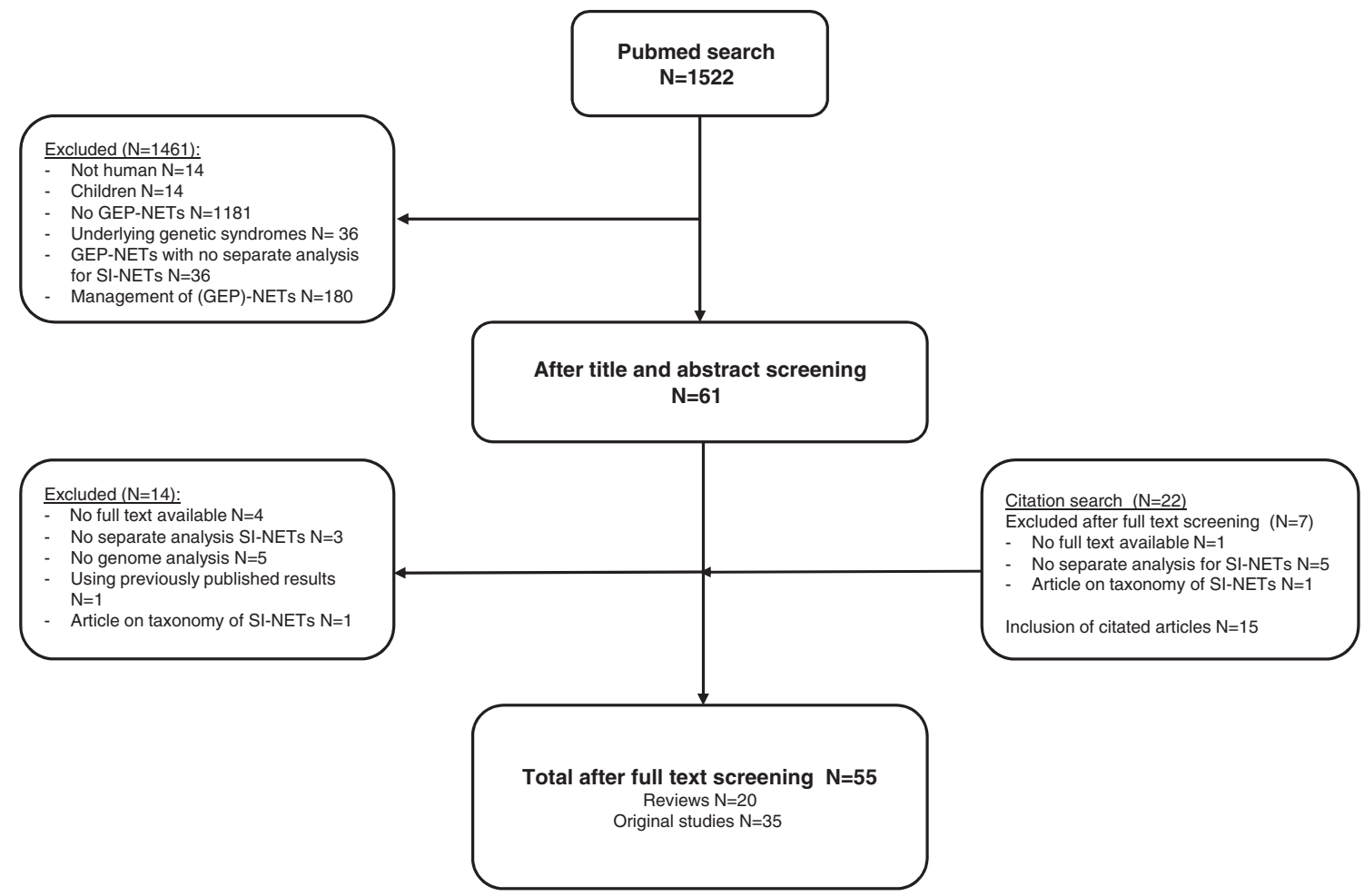

Figure 1

Flowchart of search and screening process in PubMed.

14 articles were excluded. The citation search identified 22 additional articles of which 7 were excluded. In total 55 relevant articles were found, consisting of 20 reviews and 35 original studies. The results of the selected original studies are shown in Table 2. Our review will discuss the most relevant studies, with a special focus on the prognostic implications of the identified molecular alterations. The identified studies describe different genomic events and altered expression of several proteins which play a key role in various molecular pathways involved in SI-NET tumorigenesis. Events which have been described in multiple studies and are discussed in this paper are shown in Fig. 2.

\section{Genetics of SI-NETs}

\section{Chromosomal aberrations}

From genomic profile studies, two different groups of SI-NETs can be identified, one which is characterised by loss of heterozygosity (LOH) of chromosome 18 as an early event and the other group which has no alterations of chromosome 18 and shows clustered gains on chromosomes 4, 5, 7, 14 and $20(11,12,13,14,15)$.

Multiple studies reported loss of one copy of chromosome 18, with an incidence of $44-100 \%$ in primary SI-NETs $(11,12,13,14,15,16,17,18,19,20$, $21,22)$. Chromosome 18 harbours several candidate tumour suppressor genes, including DCC (deleted in colorectal cancer; involved in axon guidance), SMAD4 (mothers against decapentaplegic homolog 4; TGFB signal transduction), SMAD2 (mothers against decapentaplegic homolog 2; TGFB signal transduction) and TCEB3C (transcriptional elongation factor $\mathrm{B}$ polypeptide $3 \mathrm{C}$; encoding Elongin A3; RNA transcription). Banck et al., who performed whole-exome sequencing (WES) on 48 well-differentiated SI-NETs, found SMAD2 and SMAD4 monoallelic deletions in 21 tumours $(23,24)$. Edfeldt et al. $(n=43)$ identified that in the majority of SI-NETs decreased expression of Elongin A3 (77\%) was present and that the remaining TCEB3C gene was epigenetically silenced by DNA hypermethylation (25).

Nieser et al. $(n=148)$ performed the first comprehensive study to identify chromosome 18 related events at genetic, epigenetic and gene/protein expression level, which only found DCC to be affected by the monoallelic loss of chromosome 18 (22). In addition, Simbolo et al. ( $n=52$ ) observed copy loss of multiple genes located on chromosome 18: CDH19 (cadherin 19; cell adhesion; $46.2 \%), \quad B L C 2$ (B-cell-lymphoma; regulation of cell death; 42.3\%), DCC (42.3\%) and SMAD4 (28.8\%) (15).

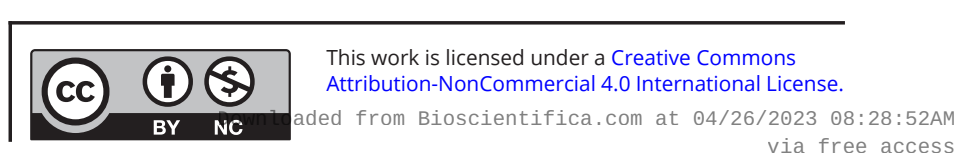



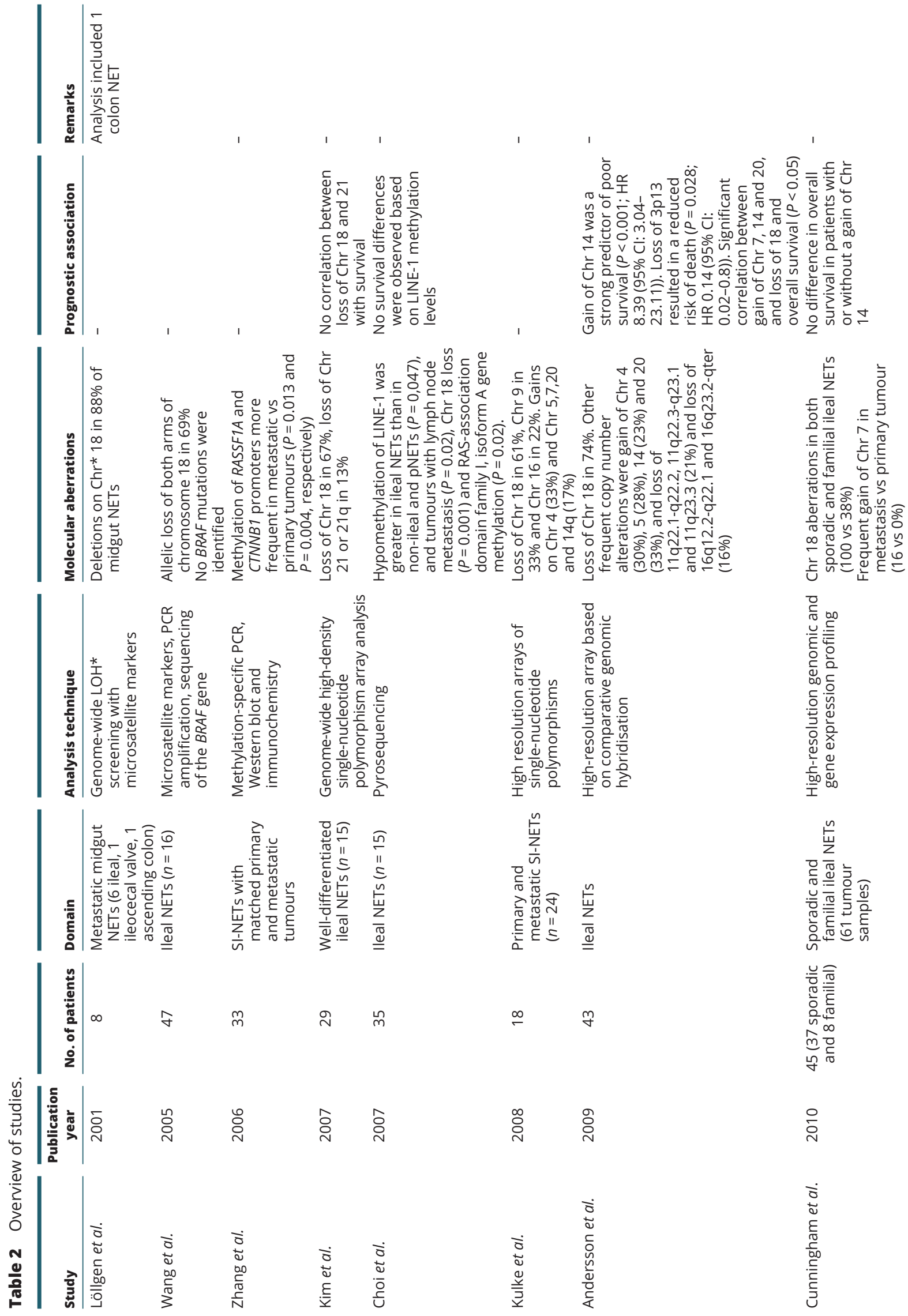

ㄱํำ

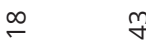

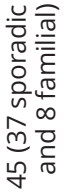

유 유

ঃ

$\frac{\circ}{\circ}$ 

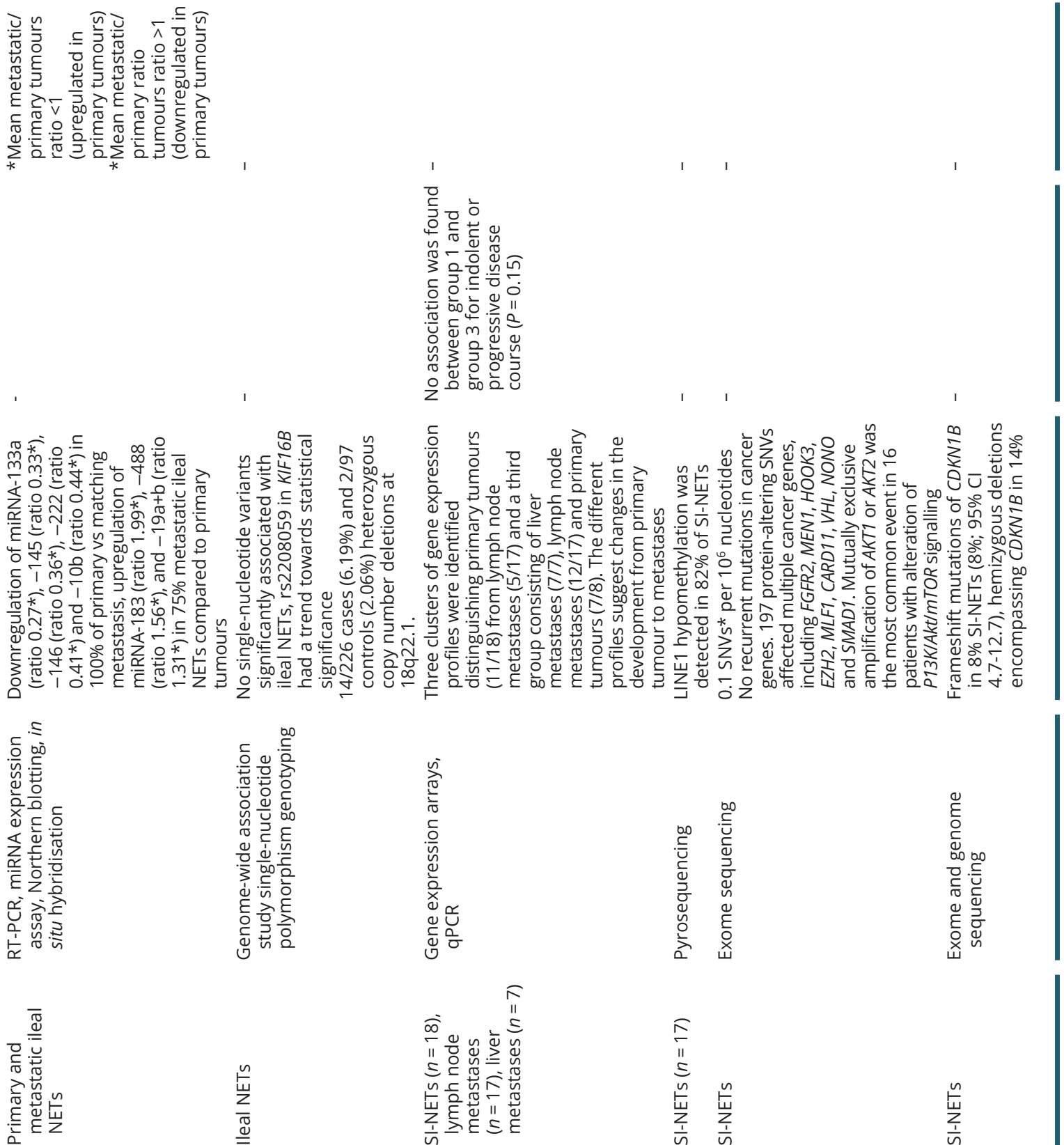

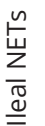

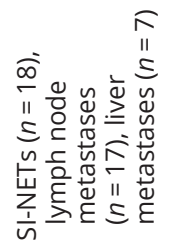

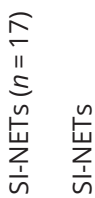

$\frac{n}{\sum_{1}}$

$\infty$

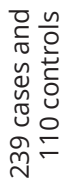

$\stackrel{9}{\circ}$

$\stackrel{\infty}{\stackrel{\infty}{+}}$

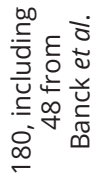

은

হৃণ

$\bar{i}$

$\stackrel{\sim}{\stackrel{n}{\circ}}$

$\stackrel{m}{i}$

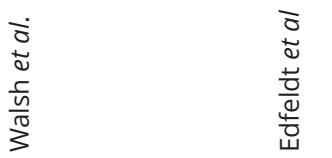



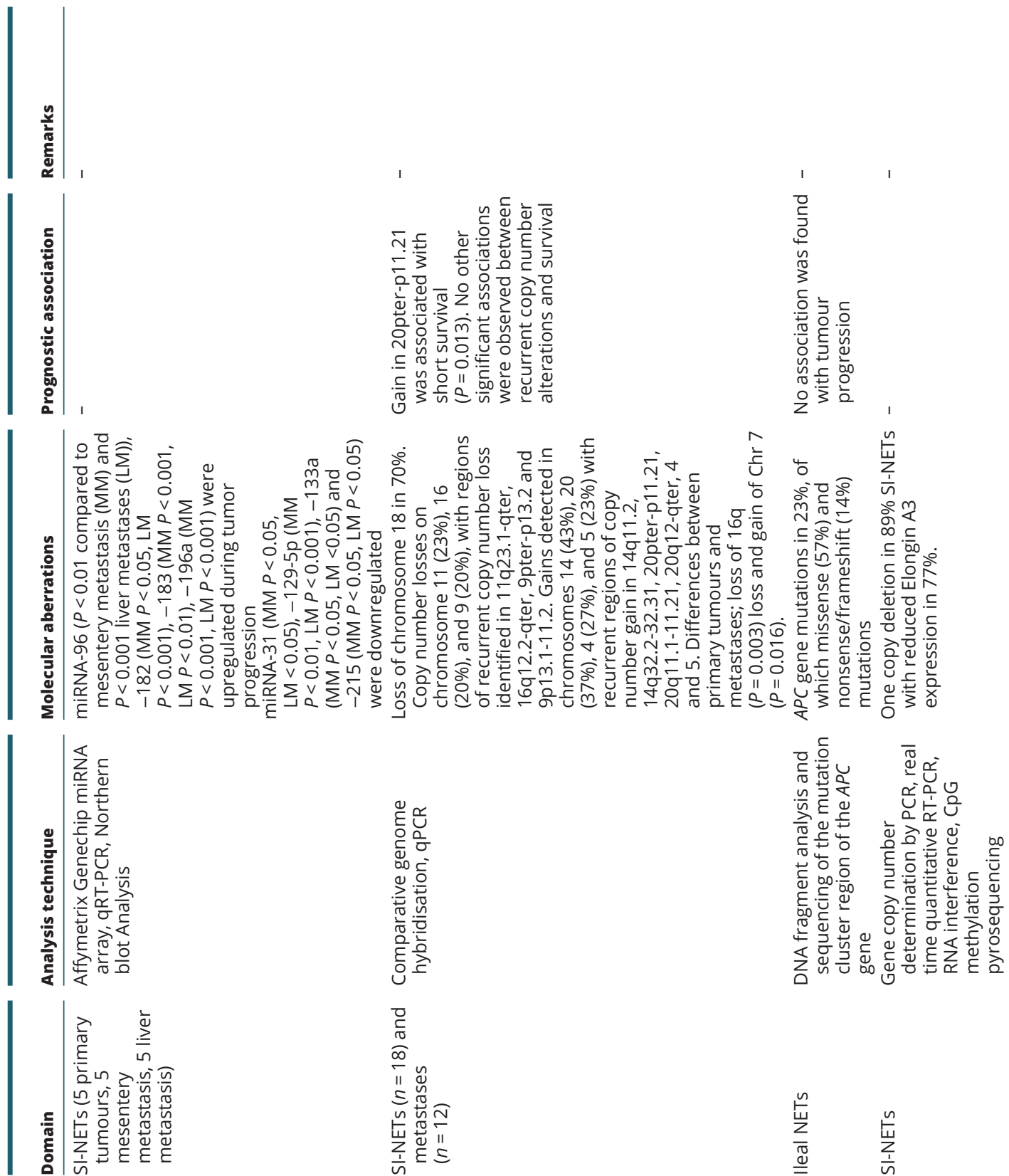

总

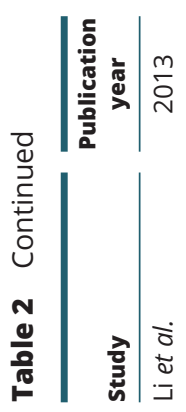

() 2019 The authors Published by Bioscientifica Ltd
요

ำฺ

$\stackrel{m}{\grave{n}}$

$\stackrel{m}{n}_{i}^{\infty}$

$\begin{array}{ll}\stackrel{n}{\underline{\underline{z}}} & \stackrel{n}{\frac{㇒}{\pi}} \\ \stackrel{1}{=} & \frac{1}{n}\end{array}$

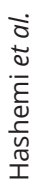

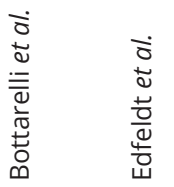

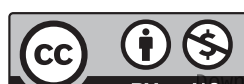

This work is licensed under a Creative Commons Attribution-NonCommercial 4.0 International License. ded from Bioscientifica.com at 04/26/2023 08:28:52AM 

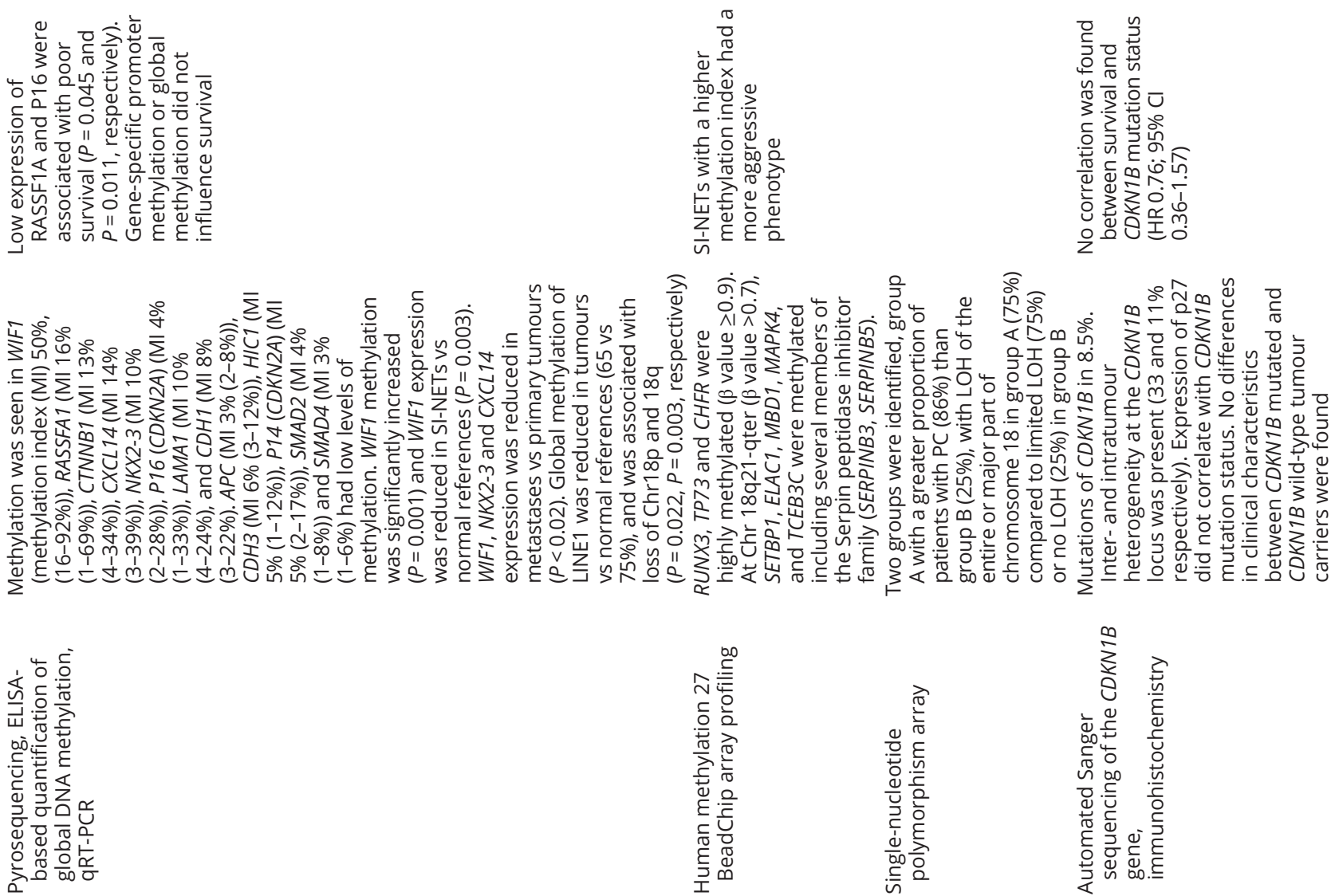

J
11
5
$\frac{n}{5}$
$\frac{\mathrm{w}}{\sum_{1}}$
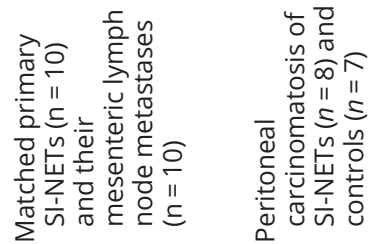

ত্
$m$
11
5
5
$\frac{n}{w}$
$\frac{1}{n}$

$\stackrel{n}{\sim}$

우

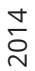

$\frac{\text { 2 }}{\text { + }}$

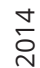

$\stackrel{n}{\stackrel{n}{N}}$ 


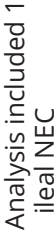
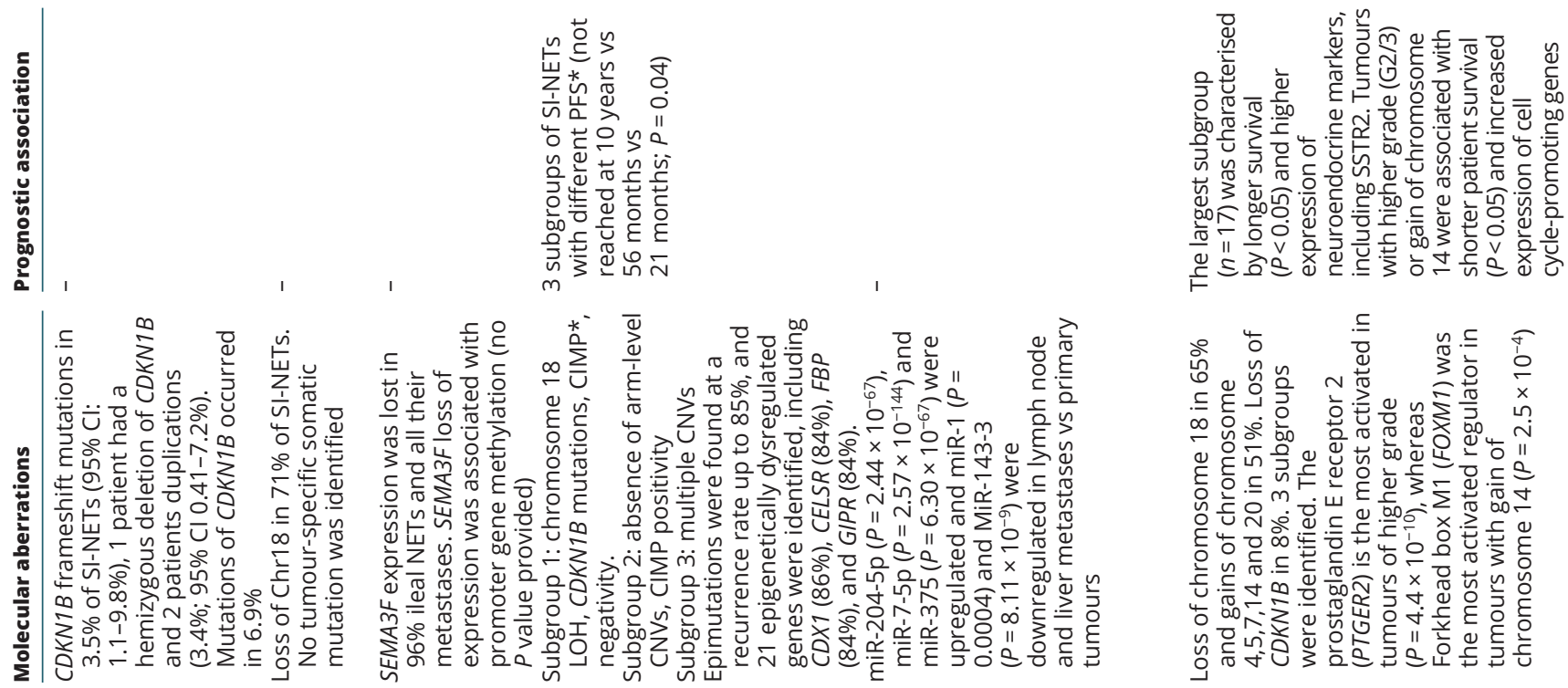

\section{-}
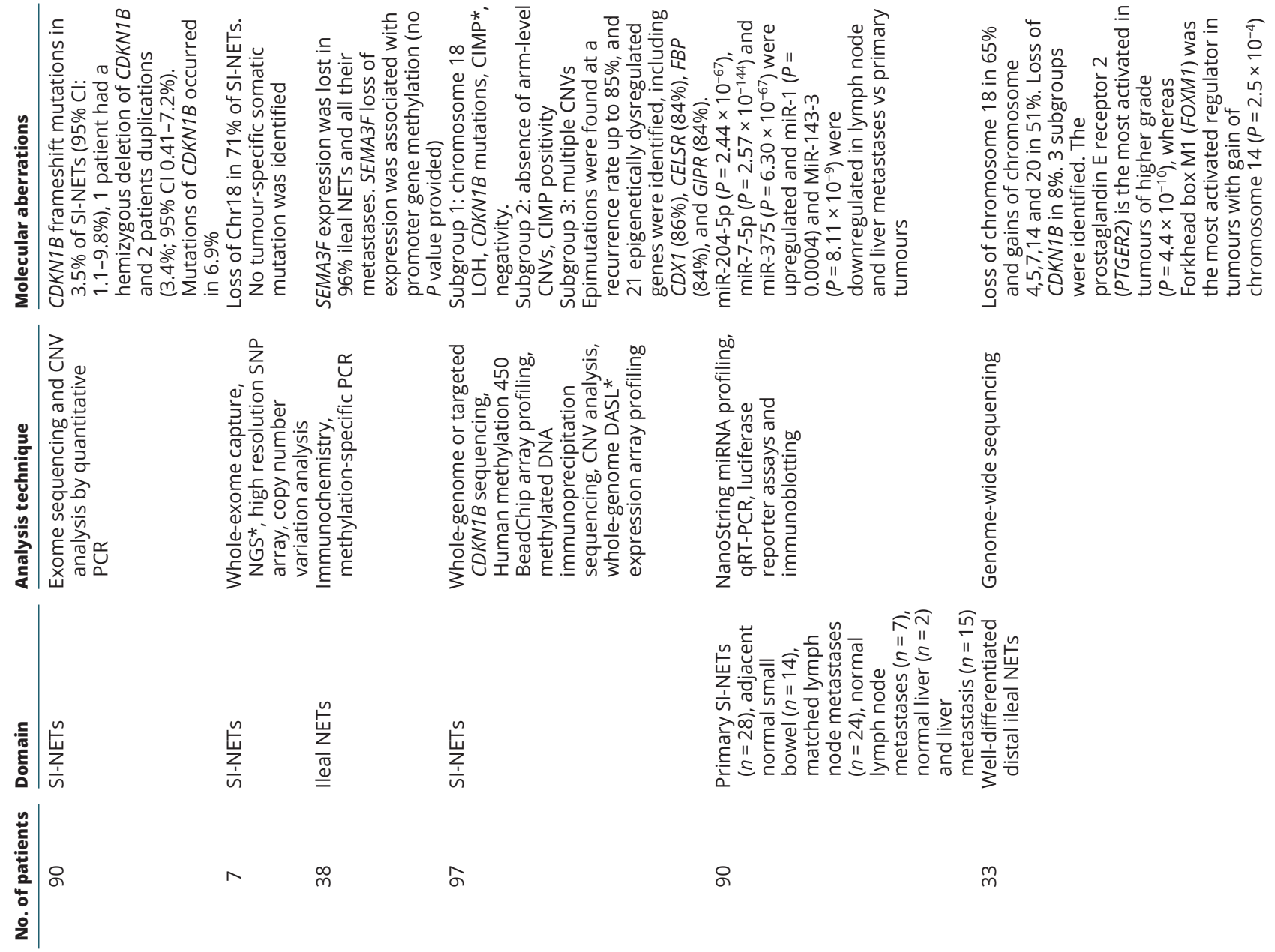

৪

m

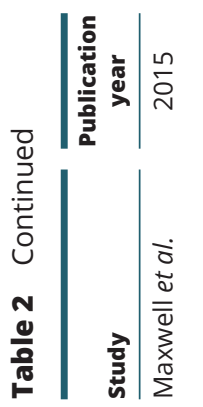

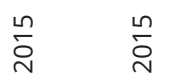

$\stackrel{\text { in }}{\stackrel{n}{2}}$

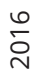

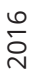

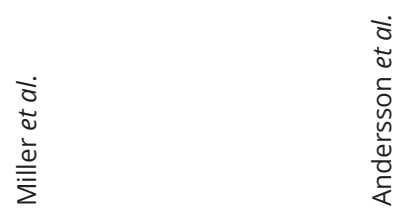

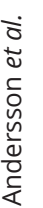

(c) 2019 The authors Published by Bioscientifica Ltd

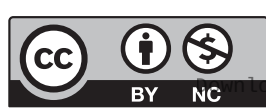

This work is licensed under a Creative Commons Attribution-NonCommercial 4.0 International License. ded from Bioscientifica.com at 04/26/2023 08:28:52AM 

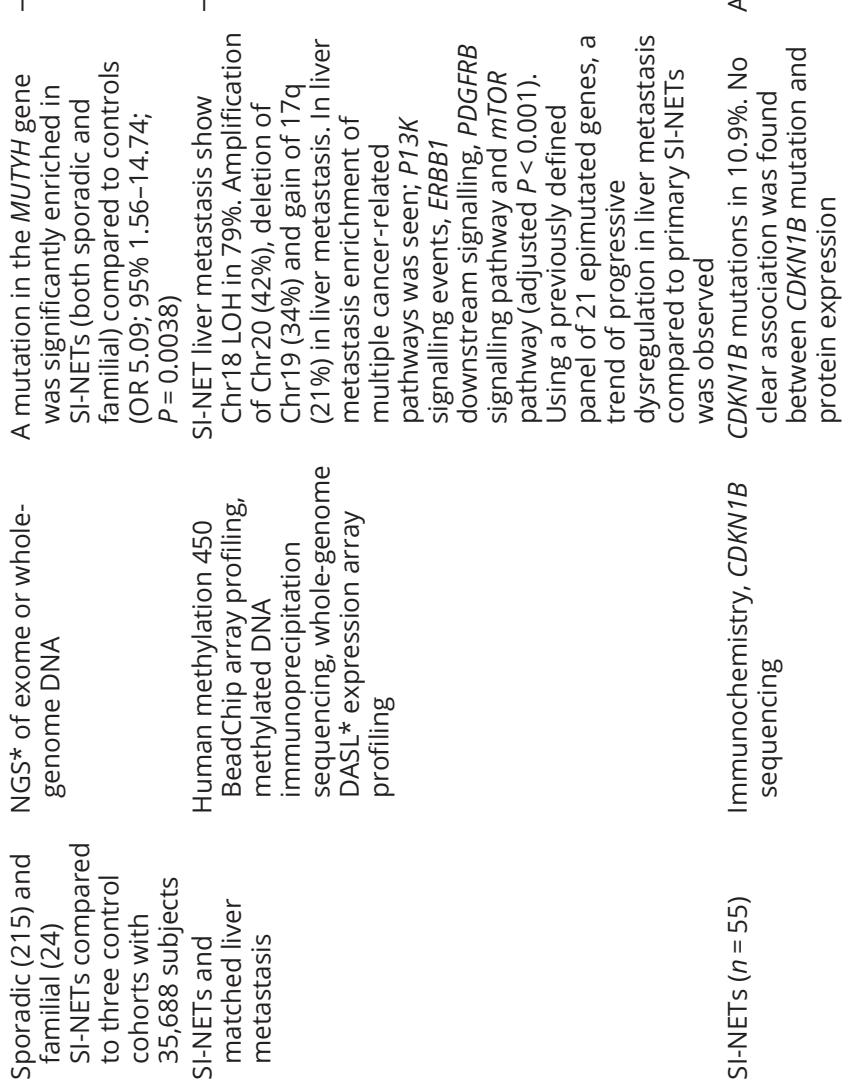

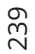

हิ

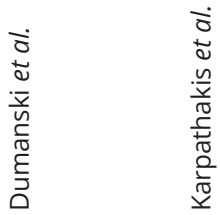

$\frac{\dot{\bar{c}}}{\stackrel{ \pm}{\bar{n}}}$
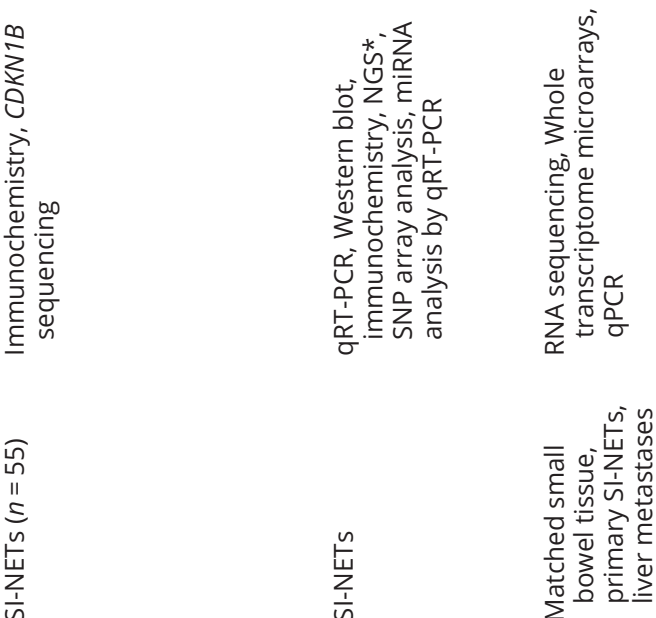

$\simeq$

$\stackrel{\text { ¿ }}{\stackrel{\infty}{\sigma}}$

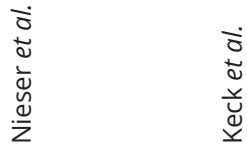

$\underset{\frac{1}{n}}{\stackrel{n}{n}}$

$\stackrel{\infty}{\sim}$

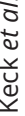

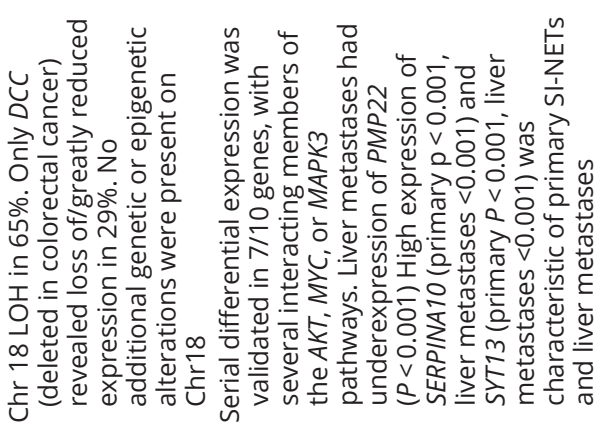

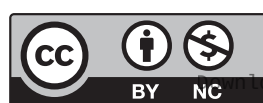

This work is licensed under a Creative Commons Attribution-NonCommercial 4.0 International License. ded from Bioscientifica.com at 04/26/2023 08:28:52AM 

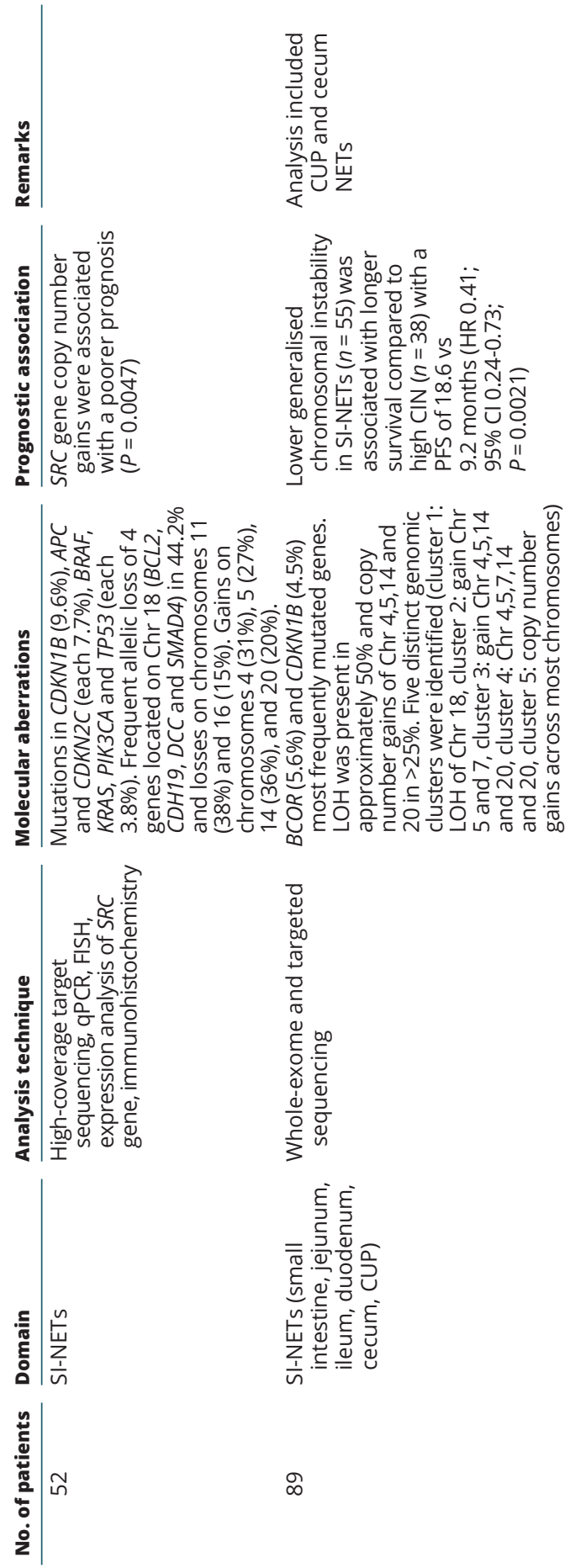

$\infty$
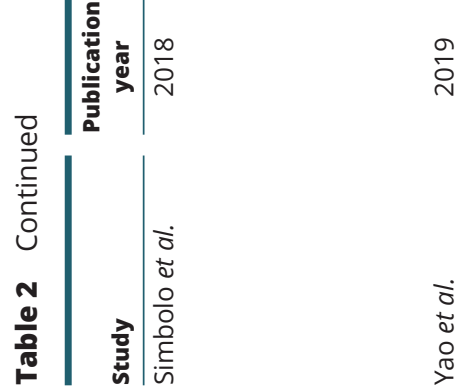

The clinical significance of LOH of chromosome 18 has been evaluated in multiple studies, either focussing solely on LOH of chromosome 18 or as part of a molecular profile study. According to Andersson et al. $(n=43) \mathrm{LOH}$ of chromosome 18 is associated with worse overall survival (13). In contrast, Kim et al. did not find a significant correlation between loss of chromosome 18 and survival (18). Contrarily, Yao et al. $(n=89)$ found that SI-NETs with low generalised chromosomal instability (CIN) (which consisted of a cluster with $\mathrm{LOH}$ of chromosome 18) displayed significantly longer median PFS than those with a high CIN (which consisted of 3 clusters with different combinations of gains of chromosome 4, 5, 7, 14,20 and 1 cluster with copy number gains across most chromosomes). PFS in patients with a low CIN $(n=55)$ was 18.6 vs 9.2 months in high CIN $(n=38)$ (HR; $0.41 ; 95 \%$ CI $0.24-0.73 ; P=0.0021)(11)$.

As described by the clusters of Yao et al., recurrent gains of chromosome 4, 5, 7, 14 and 20 are common in SI-NETs $(11,12,13,14,15,18,19,21)$. In two studies by Andersson et al., gain of chromosome 14 was seen in 6 of 32 well-differentiated SI-NETs and was associated with higher tumour grade and shorter survival (HR 8.39; 95\% CI 3.04-23.11) (13, 21). However, Cunningham et al. $(n=45)$ and Simbolo et al. $(n=52)$ could not corroborate these findings $(15,19)$. Hashemi et al. $(n=30)$ studied copy number alterations (CNAs; gains and losses of areas of the chromosome) and reported an association between gain of 20pter-p11.21 and worse survival (14), which was also not confirmed by the findings of Simbolo et al. (15). Generalised chromosomal instability seems to be a common feature of SI-NETs. This phenomenon could possibly be a reflection of diverse underlying defects in chromosomal maintenance that drive SI-NET development (11).

\section{Mutational status}

Banck et al. analysed 48 primary SI-NETs, predominantly grade 1 , by massively parallel exome sequencing and detected a low mutation rate in the SI-NET genomes with an average of 0.1 somatic single-nucleotide variants (SNVs) per $10^{6}$ nucleotides in the exome, suggesting that SI-NETs are mutationally quiet tumours (23). No recurrent mutations in the 215 sequenced target genes were found. In the studied SI-NETS, 197 protein-altering SNVs were identified, affecting a multitude of cancer genes including FGFR2, MEN1, HOOK3, EZH2, MLF1, CARD11, VHL, NONO, FANCD2, SMAD1 and BRAF. In 29\% of SI-NETs, there were genetic alterations in the $P 13 K / A K T / m T O R$ pathway and mutually exclusive amplification of $A K T 1$ or $A K T 2$ were

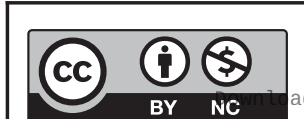

This work is licensed under a Creative Commons Attribution-NonCommercial 4.0 International License. ded from Bioscientifica.com at 04/26/2023 08:28:52AM via free access 


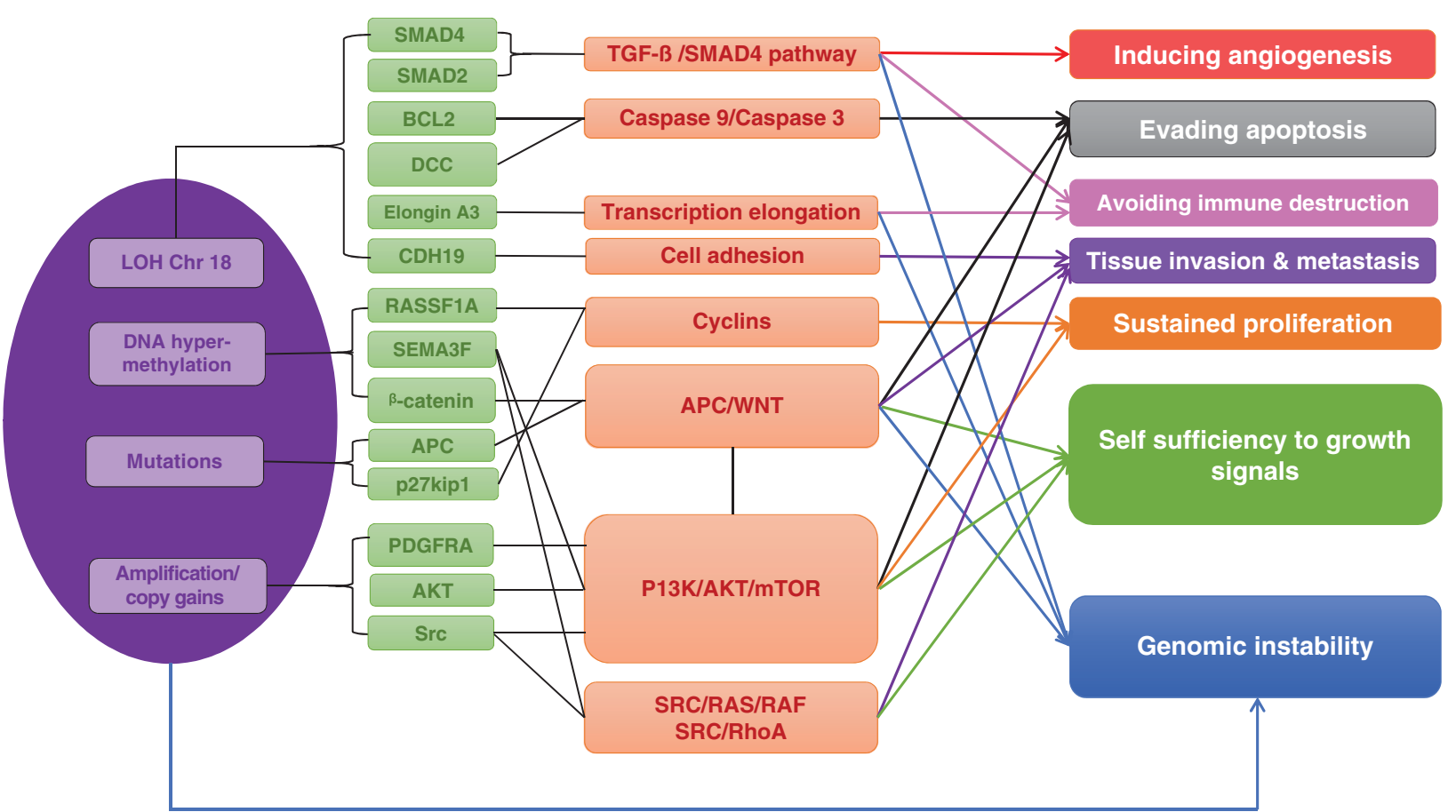

genomic alteration

protein

\section{Figure 2}

The studies presented in this review identified the deregulation of the expression of multiple genes in SI-NETs, which are commonly associated with carcinogenesis in other tumours. In the figure above, only those molecular alterations that have been found in multiple studies are depicted, together with their presumed role as key regulators of different cell functions and their possible effect on tumour progression as defined by the hallmarks of cancer (55).

common. Amplifications were also observed at the PDFDR (platelet-derived growth factor receptor alpha) locus in $20.8 \%$ (23). In a recent study by Simbolo et al. frequent copy gains were detected in AKT1 (30.8\%) and PDGFRA (platelet-derived growth factor receptor alpha: 28.8\%) as well. Furthermore, gains were present at the FOS gene (transcription factor subunit; 36.5\%), KIT (involved in cell proliferation, survival, migration and differentiation; $28.8 \%$ ) and $K D R$ (kinase insert domain receptor, involved in VEGF signalling; 28.8\%) genes (15). Higher mutation rates in primary SI-NETs were associated with increased likelihood of recurrent liver metastases $(P<0.04)(23)$. In a study by Francis et al. $(n=180)$ including 48 cases from Banck et al., heterozygous frame shift mutations of the cyclin-dependent kinase inhibitor $1 \mathrm{~B}$ gene $(C D K N 1 B)$ in 14 of 180 SI-NETs (8\%; 95\% CI 4.7-12.7\%) were observed (24). CDKN1B is located on chromosome 12 and encodes the protein $\mathrm{p} 27^{\mathrm{Kip} 1}$, a cyclin-dependent kinase inhibitor (CKI), whose main function is to control the progression from $\mathrm{G} 1$ to $S$ phase in the cell cycle. The reported mutations in this putative tumour suppressor gene in SI-NETs are loss-of-function truncating mutations throughout the gene; no hotspot has been identified.
A further study by Crona $(n=200)$, confirmed the presence of CDKN1B mutations in 17 of 200 SI-NETs (8.5\%) (95\% CI 4.6-12.4\%) (26). Mutational status did not appear to correlate with protein expression of $\mathrm{p} 27^{\mathrm{Kip} 1}$ and no immediate detectable impact on clinical phenotype and survival was found (26). Similarly, Shi et al. observed CDKN1B mutations in $10.9 \%$ of 55 SI-NETs and found no association between $C D K N 1 B$ mutation, $\mathrm{p}^{\text {kip } 1}$ expression and survival (27). Only a trend towards shorter survival of patients with tumours exhibiting low expression of p27 ${ }^{\text {kip } 1}$ (multivariate HR, 2.04; 95\% CI 1.06-3.93; $P=0.03$ ) was observed. Other studies found CDKN1B mutations in $4.5-9.6 \%$ of SI-NETs $(11,15,28,29)$. Furthermore, Yao et al., using whole-exome and targeted panel sequencing on 89 SI-NETs from the RADIANT trials, found recurring mutations in BCOR (BCL-6-interacting corepressor) in $5.6 \%$ (11). BCOR has interactions with histone deacetylases which are involved in the regulation of gene expression through DNA methylation (11). Another recent study, by Simbolo et al., performed targeted sequencing on 52 primary SI-NETs of which $34.6 \%$ showed somatic mutations (15). APC (adenomatous polyposis coli; Wnt signalling pathway regulator) and CDKN2C

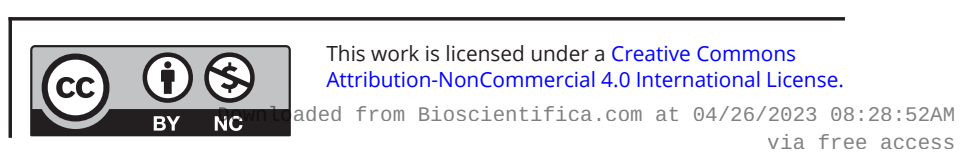


(CKI 2C; cell growth regulator which controls cell cycle G1 progression) were found to be recurrently mutated in $7.7 \%$. In addition, mutations were found in known oncogenes such as $B R A F$ (involved in MAPK/ERK signalling pathway), $K R A S$ (involved in RAS/MAPK signalling pathway), PIK3CA (phosphatidylinositol-4,5-bisphosphate 3-kinase catalytic subunit alpha; involved in the P13K/AKT/mTOR pathway) and TP53 (tumour suppressor gene; regulator of cell proliferation and apoptosis) in 3.8\% (15). Previously, Bottarelli et al. $(n=30)$ described APC gene alterations in $23 \%$ of ileal NETs (30). A copy gain of the SRC gene (protooncogene; involved in cell signalling), which was present in $25 \%$ of SI-NETs, was associated with poorer prognosis $(P=0.047)(15)$. The $S R C$ gene (cell signalling, cell cycle control and cell adhesion) was also the most commonly amplified oncogene $(23 \%)$ in the study by Banck et al. (23). Copy gains of the $S R C$ gene could potentially be a novel prognostic biomarker, especially as whole-genome sequencing becomes more widely adopted into clinical practice of SI-NETs.

\section{Molecular alterations in primary tumours vs metastases}

Molecular differences between primary tumours vs metastases can provide insight in the process of tumour progression. Cunningham et al. observed increased gains of chromosome 7 in metastases (30 mesenterial and 4 hepatic) vs primary SI-NETs (16 vs 0\%) (19). Correspondingly, Hashemi et al. reported frequent gain of 7q22.3-qter in metastases (12 regional and 7 distant; $P=0.016)$ compared to primary tumours (14). Loss of 16q12.2qter was more common in distant metastases vs primary tumours $(P=0.003)(14)$. Karpathakis found LOH of chromosome 18 in 79\% in liver metastases (31). In the same study, amplification of chromosome 20 was found in $42 \%$, deletion of chromosome 19 in 34\% and gain of chromosome $17 q$ in $21 \%$ of liver metastases (31). Furthermore, at mRNA level, analysis of differentially expressed genes between liver metastases and primary tumours identified significant enrichment of multiple cancer-related pathways overexpressed in liver metastasis, for example P13K signalling events, ERBB1 downstream signalling, PDGFRB signalling and the $m T O R$ pathway (adjusted $P<0.001$ ) (31). Keck et al. demonstrated by RNA sequencing that liver metastases show underexpression of PMP22 (peripheral myelin protein 22; integral membrane protein involved in demyelinating disease and apoptosis) compared to the corresponding primary tumour $(<0.001)$ (32). Fotouhi et al. $(n=33)$ found different expression levels of CXCL14 (chemokine CXC motif ligand 14; involved in cytokine activity and angiogenesis) mRNA in metastases compared to primary tumours $(P=0.0016)$, which correlated with methylation status of the respective genes (33). Furthermore, increased expression was found for mRNA encoding beta-catenin (involved in Wnt signalling pathway) in metastases compared with primary tumours $(P=0.041)$; for mRNA encoding P16 (regulates entry into $S$ phase) in distant metastasis compared to primary tumours and regional metastases $(P=0.015)$ and for mRNA encoding RASSF1A (involved in cell cycle regulation, apoptosis and migration), in regional metastases compared to primary tumours and distant metastases $(P=0.008)$. Low mRNA expression of RASSF1A and P16 were each associated with short survival ( $P=0.045$ and $P=0.011$, respectively) (33). Using gene expression arrays, Edfeldt et al. were able to identify differentially expressed mRNA in SI-NET metastases compared to primary tumours which resulted in the identification of three different gene expression clusters. However, these clusters did not correlate with tumour progression (34). To conclude, dissemination of SI-NETs is associated with genomic events; yet the way in which these events contribute to tumour progression remains unclear.

\section{Prognostic stratification based on LOH of chromosome 18, CDKN1B mutations, CpG island methylator phenotype and copy number variations}

Karpathakis et al. identified different prognostic subgroups using hierarchical clustering. In a sophisticated large-scale integrated genomic analysis, including DNA methylation, gene expression and copy number variance (CNV) of 97 SI-NETs from a cohort of 85 patients they identified three molecular subtypes of SI-NETs using an integrated genome analysis (29). The largest subgroup (55\%) was defined by chromosome $18 \mathrm{LOH}$ and is associated with the presence of CDKN1B mutations, and $\mathrm{CpG}$ island methylator phenotype (CIMP) negativity. The CpG island methylator phenotype refers to the DNA hypermethylation of promoter-associated $\mathrm{CpG}$ islands of tumour suppressor and DNA repair genes, which leads to transcriptional silencing of these genes. These patients had the most favourable PFS (not reached at 10-year follow-up) after resection and a median age of 67 years at diagnosis. A second subgroup (18\%) was characterised by the absence of arm-level CNVs (copy number variations that span the chromosomal arm) and a high degree of CIMP positivity. This group had an intermediate PFS (56 months) and a younger median age at diagnosis (60 years). The third subgroup consisted of 
$26 \%$ of SI-NETs and was characterised by multiple CNVs; these patients had a significantly poorer PFS (21 months) and were youngest at onset (54 years), suggesting a more aggressive clinical phenotype. In accordance with Karpathakis et al., Yao et al. $(n=89)$, identified similar prognostic groups regarding $\mathrm{LOH}$ of chromosome 18 and alterations in chromosome 4, 5 and 20 (11). However, Simbolo et al. classified their cohort $(n=52)$ into the three molecular groups of Karpathakis et al. and did not observe any statistically significant correlation with prognosis $(P=0.73)(15)$. These results of Simbolo et al. could be due to the relatively small cohort in comparison to the cohort of Karpathakis et al. and do not necessarily weaken the findings of Karpathakis and Yao et al. Based on the findings of Karpathakis et al. and considering the relatively low frequency of somatic mutations in SI-NETs, it seems unlikely that mutations of the CDKN1B gene or LOH of chromosome 18 alone are driving the SI-NET tumorigenesis and suggests a greater role for epigenetic dysregulation $(11,15,20,25,29,35)$.

\section{Germline mutations in SI-NETs}

A germline mutation is defined as a mutation which occurs in reproductive cells and therefore is incorporated in every cell of the offspring. A study by Dumanski et al. $(n=239)$ sequenced germline DNA from 24 patients from 15 families with a history of SI-NETs and from 215 sporadic SI-NET patients (36). A mono-allelic mutation causing an amino-acid substitution p. (Gly396Asp) in MUTYH was found to be significantly enriched in both patients affected with familial SI-NETs and in sporadic SI-NETs, compared to controls (minor allele frequencies 0.013 and 0.03 , respectively) with an odds ratio of 5.09 (95\% CI 1.56-14.74; $P=0.0038$ ). MUTYH encodes a DNA glycosylase, involved in repair of oxidative DNA damage in order to prevent mutation accumulation leading to tumorigenesis. Biallelic germline MUTYH mutations lead to multiple colorectal adenomas and carcinomas, referred to as MUTYH-associated polyposis (MAP), a recessive hereditary colorectal polyposis syndrome. Interestingly, MUTYH germline mutations were also found in pancreatic NETs $(10,37)$. By defective DNA repair, carriers with MUTYH mutations thus seem to have a predisposition to develop NETs of the pancreas or small intestine.

\section{Epigenetics in SI-NETs}

Epigenetic modification can be defined as a change in gene expression without alterations to the gene's DNA sequence itself (38). Since SI-NETs appear to have relatively few somatic mutations, epigenetic dysregulation could play an important role in the tumorigenesis of SI-NETs and may have important clinical implications $(23,24$, 35). Epigenetic changes include DNA methylation, histone modifications and the actions of miRNA. Hypermethylation and hypomethylation and histone modifications modify gene expression, whereas miRNAs, small single-stranded RNA molecules, regulate gene expression post-transcriptionally.

These processes can be pharmacologically modified by targeting enzymes involved in DNA methylation and histone modifications, and by miRNA inhibitors, thereby representing an appealing target for therapy $(35,39)$.

In comparison with genetic mutations, epigenetic alterations are significantly more common and recurrent in SI-NETs. Our search yielded studies ranging from 8 to 97 patients that showed epigenetic alterations in SI-NETs for example DNA methylation changes in $65-82 \%$ of SI-NETs and multiple miRNA deregulations $(29,40,41,42)$. Several studies reported differences in methylation and miRNA patterns between primary tumours and metastases, suggesting a possible role in tumour development or progression. A recurrent event is the epigenetic silencing of RASSFIA (RAS-association domain family 1, isoform A gene; tumour suppressor gene inducing cell cycle arrest) expression by hypermethylation of its promotor. This event was observed by Choi et al., Zhang et al. and Fotouhi et al. and was more prominent in metastases than in primary tumours $(33,43,44)$. In addition, increased hypermethylation of the CTNNB1 promoter was observed in liver metastasis compared to the corresponding primary tumours (44). Promotor gene methylation was also found in a study by Bollard et al. $(n=38)$ in $96 \%$ of ileal NETs and their metastases. The expression of the axon guidance molecule SEMA3F (semaphorin 3F) was lost due to hypermethylation (45). SEMA3F expression is a negative regulator of MAPK and $m T O R$ signalling pathways.

The first genome-wide DNA methylation analysis of SI-NETs performed by Verdugo et al. in 10 SI-NETs and ten matched mesenteric lymph node metastasis observed a high level of methylation in another gene set located at chromosome 18q21-qter (46). In these patients, high methylation index correlated with more malignant behaviour.

Karpathakis et al. found hypermethylation of the promoter region of the gastric inhibitory polypeptide receptor (GIPR; inhibits gastric secretion and gastrin release and stimulates insulin release) gene body in $74 \%$ of primary SI-NETs. Of note, in this study DNA 
methylation in SI-NETs was compared to the methylation status of normal intestinal mucosa which normally expresses GIPR, whereas the methylation status of enterochromaffin cells in the small intestine is unknown. Progressive hypermethylation of this gene was seen in liver metastases compared to primary tumours $(29,31)$.

\section{MicroRNAs in primary tumours vs. metastases}

Two miRNA profiling studies ( $n=8, n=24$, respectively) comparing primary SI-NETs to its respective metastases found multiple miRNAs to be deregulated during tumour progression $(40,47)$. A downregulation of miRNA-133a and upregulation of miR-183 was consistently found in metastases vs primaries. A study by Miller et al. $(n=28)$ confirmed downregulation of miRNA133a and found differential expression of several other miRNAs in SI-NETs and their metastases (48).

\section{Discussion}

SI-NETs are rare tumours with a relatively indolent course. Unfortunately, treatment options are limited with minimal survival benefit. Therapies targeting somatostatin receptors, expressed by the majority of SI-NETs, are only able to stagnate disease progression temporarily. In an attempt to identify prognostic factors and new effective targets for precision medicine, the genomic landscape of SI-NETs has been under increasing investigation in recent years. $\mathrm{LOH}$ at chromosome 18 remains the most frequent genomic aberration (44-100\%) found in SI-NETs (11, 12, $13,14,15,16,17,18,19,20,21,22)$.

The tumour suppressor gene, $C D K N 1 B$, is mutated in approximately $8 \%$ SI-NET patients $(11,15,26,27,28,29)$. Interestingly, $C D K N 1 B$ is regulated by menin, the protein that is defect in the majority of patients with the inheritable MEN 1 syndrome (75-80\%). Moreover, in MEN1 patients without mutations in the gene encoding menin (20-25\%), CDKN1B was shown to be inactivated in some individuals (3.6\%) (49). Thus, several SI-NETs and MEN1-associated endocrine tumours may share a common oncogenic pathway. Genetic alterations in the $P 13 K / A K T / m T O R$ were found in primary SI-NETs and liver metastasis, providing a rationale for the use of mTOR inhibitors $(15,23,31$, 45 ). However, a correlation between efficacy and mTOR mutational status prior to commencement of therapy with mTOR inhibitors has not yet been established. Daskalakis et al. $(n=27)$ recently tested the ex vivo activity of several targeted kinase inhibitors and found great variability in ex vivo sensitivity for most drugs, emphasising the need for predictive biomarkers which could support clinical decision making (50).

Furthermore, mutations in APC, CDKN2C (both 7.7\%) and BRAF, KRAS, PIK3CA and TP53 (each 3.8\%) were recently identified in SI-NETs (15).

An association of (epi)genetic aberrations with prognosis was found in 16 of the 35 original studies reviewed. Karpathakis et al. $(n=97)$ and Yao et al. $(n=89)$ identified molecular subtypes of SI-NETs with significant difference in PFS $(11,31)$. However, validation of these subgroups in an independent and larger cohort is required before translation into clinical practice is possible. A gain of chromosome 14 and 20pter-p11.21 was associated with shorter survival in two studies $(P<0.001$, $P<0.013$ respectively) $(13,14)$. SRC copy number gains were associated with poorer prognosis $(P=0.047)$ (11). Epigenetic alterations such as specific promotor methylation and global methylation and their effect on prognosis are yet to be determined $(33,41,43,44,45,46)$.

At present, predictive or prognostic biomarkers, which can be adopted into clinical practice, have not yet been established. Inactivated tumour suppressor genes, which are found in SI-NETs, are generally unsuitable as targets since restoring the function of tumour suppressor genes is difficult to accomplish. Mutations in oncogenes, which should be easier to target, have only recently been described in small numbers in SI-NETs and thus far no clinical studies have been undertaken to target these mutations in SI-NETs. Of note, Alvarez et al. identified the HDAC class inhibitor Etinostat as potent inhibitor of master regulatory activity for $42 \%$ of metastatic gastroenteropancreatic NETs, leading to the initiation of a clinical trial (NTC03211988) (9).

The low mutational burden found in SI-NETS may render these tumours less eligible for immunotherapy using immune checkpoint inhibitors because tumour mutational burden is an important determinant of clinical benefit to immune checkpoint blockade in most tumours. Additionally, the recently characterised tumour microenvironment in NETs, for example low expression for PD1 and PDL1 in SI-NETs, combined with a modest T-cell infiltrate, further tempers expectations regarding a response to the currently used PD1 and PDL-1 inhibitors, although this remains to be investigated (51).

More promising targets in SI-NETs may constitute the DNA methylation machinery. In comparison with genetic mutations, epigenetic alterations are significantly more common in SI-NETs. Specific genes such as RASSF1A, SEMA3F and CTNNB1 are hypermethylated in SI-NETs silencing their transcription $(3,43,44,45,46)$.

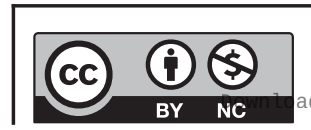


RASSF1A hypermethylation is also observed in pancreatic NETs, lung NETs and thymic NETs, whilst it is not found in appendiceal NETs (52). During the last decades, an increasing number of drugs targeting DNA methylation and histone methylation have been developed and successfully tested pre-clinically which are currently in evaluation in phase I-III clinical trials (53). Additionally, the more specific upregulation of miRNAs in SI-NETS as described above may provide actionable targets since multiple strategies for miRNA-based therapies are under investigation (54).

In this era of accumulating studies regarding the molecular background of SI-NETs, we felt there was an unmet need to provide the clinician with an overview of (epi)genetic alterations and explain their relevance in terms of prognosis and possible novel therapeutic options. Despite our efforts to perform an extensive and broad search, studies may have been missed due to its non-systemic character. Limitations of studies used in this reviewincluderelativelysmallandheterogeneous cohorts, different genomic analysis techniques and paucity of relation of (epi)genetic aberrations to clinical outcomes.

The rarity of SI-NETs has hampered conducting sizeable clinical trials involving large-scale integrated genomic analysis. In the coming years, hopefully international collaborations will enable larger studies to be performed which correlate (epi)genetic alterations to clinical outcomes and aim to identify targetable (epi)genetic alterations. Larger studies combined with evolving molecular technologies might lead to a more effective treatment strategy in which patients with specific molecular tumour profiles will be selected for targeted pharmaceutical interventions.

\section{Conclusion}

SI-NETs have a low mutational burden, whereas epigenetic alterations are more prevalent. Mutations as described in pancreatic NETs are generally not observed in SI-NETs. Several studies identified (epi)genetic subtypes and molecular profiles of SI-NETs with significant difference in progression-free survival (PFS) and overall survival (OS). More research should be conducted to identify prognostic and predictive biomarkers that can be adopted in clinical decision making.

\section{Declaration of interest}

The authors declare that there is no conflict of interest that could be perceived as prejudicing the impartiality of the research reported.

\section{Funding}

This work did not receive any specific grant from any funding agency in the public, commercial or non-profit sector.

\section{References}

1 Yao JC, Hassan M, Phan A, Dagohoy C, Leary C, Mares JE, Abdalla EK, Fleming JB, Vauthey JN, Rashid A, et al. One hundred years after 'carcinoid': epidemiology and prognostic factors for neuroendocrine tumors in 35,825 cases in the United States. Journal of Clinical Oncology 200826 3063-3072. (https://doi.org/10.1200/ JCO.2007.15.4377)

2 Hallet J, Law CH, Cukier M, Saskin R, Liu N \& Singh S. Exploring the rising incidence of neuroendocrine tumors: a population-based analysis of epidemiology, metastatic presentation, and outcomes. Cancer 2015121 589-597. (https://doi.org/10.1002/cncr.29099)

3 Garcia-Carbonera R, Jilmenez-Fonseca P, Teulé A, Barriuso J, Sevilla I \& Spanish Society for Medical Oncology. SEOM clinical guidelines for the diagnosis and treatment of gastroenteropancreatic neuroendocrine neoplasms (GEP-NENs) 2014. Clinical and Translational Oncology 201416 1025-1034. (https://doi.org/10.1007/ s12094-014-1214-6)

4 Hassan SA, Banchs J, Iliescu C, Dasari A, Lopez-Mattei J \& Yusuf SW. Carcinoid heart disease. Heart 2017103 1488-1495. (https://doi. org/10.1136/heartjnl-2017-311261)

5 Dasari A, Shen C, Halperin D, Zhao B, Zhou S, Xu Y, Shih T \& Yao JC. Trends in the incidence, prevalence, and survival outcomes in patients with neuroendocrine tumors in the United States. JAMA Oncology 20173 1335-1342. (https://doi.org/10.1001/ jamaoncol.2017.0589)

6 Pan SY \& Morrisson H. Epidemiology of cancer of the small intestine. World Journal of Gastrointestinal Oncology 20113 33-42. (https://doi. org/10.4251/wjgo.v3.i3.33)

7 Zatelli MC, Fanciulli G, Malandrino P, Ramundo V, Faggiano A, Colao A \& NIKE Group. Predictive factors of response to mTOR inhibitors in neuroendocrine tumours. Endocrine-Related Cancer 2016 23 R173-R183. (https://doi.org/10.1530/ERC-15-0413)

8 Singh S, Carnaghi C, Buzzoni R, Pommier RF, Raderer M, Tomasek J, Lahner H, Valle JW, Voi M, Bubutishvili-Pacaud L, et al. Everolimus in neuroendocrine tumors of the gastrointestinal tract and unknown primary. Neuroendocrinology 2018106 211-220. (https://doi. org/10.1159/000477585)

9 Alvarez MJ, Subramaniam PS, Tang LH, Grunn A, Aburi M, Rieckhof G, Komissarova EV, Hagan EA, Bodei L, Clemons PA, et al. A precision oncology approach to the pharmacological targeting of mechanistic dependencies in neuroendocrine tumors. Nature Genetics 201850 979-989. (https://doi.org/10.1038/s41588-018-0138-4)

10 Scarpa A, Chang DK, Nones K, Corbo V, Patch A, Bailey P, Lawlor RT, Johns AL, Miller DK, Mafficini A, et al. Whole-genome landscape of pancreatic neuroendocrine tumours. Nature 2017543 65-71. (https://doi.org/10.1038/nature21063)

11 Yao JC, Garg A, Chen D, Capdevila J, Engstorm P, Pommier R, van Cutsem E, Singh S, Fazio N, He W, et al. Genomic profiling of NETs: a comprehensive analysis of the RADIANT trials. Endocrine-Related Cancer 201926 391-403. (https://doi.org/10.1530/ERC-18-0332)

12 Kulke MH, Freed E, Chiang DY, Philips J, Zahrieh D, Glickman JN \& Shivdasani RA. High-resolution analysis of genetic alterations in small bowel carcinoid tumor reveals areas of recurrent amplification and loss. Genes, Chromosomes and Cancer 200847 591-603. (https:// doi.org/10.1002/gcc.20561)

13 Andersson E, Swärd C, Stenman G, Ahlman H \& Nillson O. Highresolution genomic profiling reveals gain of chromosome 14 as a predictor of poor outcome in ileal carcinoids. Endocrine-Related Cancer 200916 953-966. (https://doi.org/10.1677/ERC-09-0052)

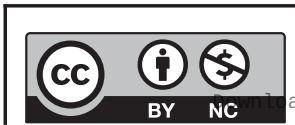

This work is licensed under a Creative Commons Attribution-NonCommercial 4.0 International License. ded from Bioscientifica.com at 04/26/2023 08:28:52AM 
14 Hashemi J, Fotouhi O, Sulaiman L, Kjellman M, Höög A, Zedenius J $\&$ Larsson C. Copy number alterations in small intestinal neuroendocrine tumors determined by array comparative genomic hybridization. BMC Cancer 201313 505. (https://doi. org/10.1186/1471-2407-13-505)

15 Simbolo M, Vincentini C, Maffacini A, Fassan M, Pedron S, Corbo V, Mastracci L, Rusev B, Pedrazzani C, Landoni L, et al. Mutational and copy number asset of primary sporadic neuroendocrine tumors of the small intestine. Virchows Archiv 2018473 709-717. (https://doi. org/10.1007/s00428-018-2450-x)

16 Löllgen RM, Hessman O, Szabo E, Westin G \& Akerstörm G. Chromosome 18 deletions are common events in classical midgut carcinoid tumors. International Journal of Cancer 200192 812-815. (https://doi.org/10.1002/ijc.1276)

17 Wang GG, Yao JC, Worah S, White JA, Luna R, Wu T, Hamilton SR $\&$ Rashid A. Comparison of genetic alterations in neuroendocrine tumors: frequent loss of chromosome 18 in ileal carcinoid tumors. Modern Pathology 200518 1079-1087. (https://doi.org/10.1038/ modpathol.3800389)

18 Kim DH, Nagano Y, Choi IS, White JA, Yao JC \& Rashid A. Allelic alterations in well-differentiated neuroendocrine tumors (carcinoid tumors) identified by genome-wide single nucleotide polymorphism analysis and comparison with pancreatic endocrine tumors. Genes, Chromosomes and Cancer 200847 84-92. (https://doi.org/10.1002/ gcc.20510)

19 Cunningham JL, Díaz de Ståhl T, Sjöblom T, Westin G, Dumanski JP \& Janson ET. Common pathogenetic mechanism involving human chromosome 18 in familial and sporadic ileal carcinoid tumors. Genes, Chromosomes and Cancer 201150 82-94. (https://doi. org/10.1002/gcc.20834)

20 Delgado Verdugo A, Crona J, Maharjan R, Hellman P, Westin G \& Björklund P. Exome sequencing and CNV analysis on chromosome 18 in small intestinal neuroendocrine tumors: ruling out a suspect? Hormone and Metabolic Research 201447 452-455. (https://doi. org/10.1055/s-0034-1389992)

21 Andersson E, Arvidsson Y, Swärd C, Hofving T, Wängberg B, Kristiansson E \& Nillson O. Expression profiling of small intestinal neuroendocrine tumors identifies subgroups with clinical relevance, prognostic markers and therapeutic targets. Modern Pathology 2016 29 616-629. (https://doi.org/10.1038/modpathol.2016.48)

22 Nieser M, Henopp T, Brix J, Stoß L, Sitek B, Naboulski W, Anlauf M, Schlitter AM, Klöppel G, Gress T, et al. Loss of chromosome 18 in neuroendocrine tumors of the small intestine: the enigma remains. Neuroendocrinology 2017104 302-312. (https://doi. org/10.1159/000446917)

23 Banck MS, Kanwar R, Kulkarni AA, Boora GK, Metge F, Kipp BR, Zhang L, Thorland EC, Minn KT, Tentu R, et al. The genomic landscape of small intestine neuroendocrine tumors. Journal of Clinical Investigation 2013123 2502-2508. (https://doi.org/10.1172/ JCI67963)

24 Francis JM, Kiezun A, Ramos AH, Serra S, Pedamallu CS, Qian ZR, Banck MS, Kanwar R, Kulkarni AA, Karpathakis A, et al. Somatic mutation of CDKN1B in small intestine neuroendocrine tumors. Nature Genetics 201345 1483-1486. (https://doi.org/10.1038/ ng.2821)

25 Edfeldt K, Ahmad T, Akerström G, Janson ET, Hellman P, Stålberg P, Björklund P \& Westin G. TBEB3C a putative tumor suppressor gene of small intestinal neuroendocrine tumors. Endocrine-Related Cancer 201421 275-284. (https://doi. org/10.1530/ERC-13-0419)

26 Crona J, Gustavsson T, Norlén O, Edfeldt K, Åkerström T, Westin G, Hellman P, Björklund P \& Stålberg P. Somatic mutations and genetic heterogeneity at the CDKN1B locus in small intestinal neuroendocrine tumors. Annals of Surgical Oncology 201522 S1428-S1435. (https://doi.org/10.1245/s10434-014-4351-9)
27 Shi Y, Qian ZR, Zhang S, Li W, Masugi Y, Li T, Chan JA, Yang J, Da Silva A, Gu M, et al. Cell cycle protein expression in neuroendocrine tumors. Pancreas 201746 1347-1353. (https://doi.org/10.1097/ MPA.0000000000000944)

28 Maxwell JE, Sherman SK, Li G, Choi AB, Bellizzi AM, O’Dorisio TM $\&$ Howe JR. Somatic alterations of CDKN1B are associated with small bowel neuroendocrine tumors. Cancer Genetics 2015208 564-570. (https://doi.org/10.1016/j.cancergen.2015.08.003)

29 Karpathakis A, Dibra H, Pipinikas C, Feber A, Morris T, Francis J, Oukrif D, Mandair D, Pericleous M, Mohmaduvesh M, et al. Prognostic impact of novel molecular subtypes of small intestinal neuroendocrine tumor. Clinical Cancer Research 201622 250-258. (https://doi.org/10.1158/1078-0432.CCR-15-0373)

30 Bottarelli L, Azzoni C, Pizzi S, D’Adda T, Silini EM, Bordi C \& Rindi G. Adenomatous polyposis coli gene involvement in ileal enterochromaffin cell neuroendocrine neoplasms. Human Pathology 201344 2736-2742. (https://doi.org/10.1016/j. humpath.2013.06.019)

31 Karpathakis A, Dibra H, Pinnikas C, Feber A, Morris T, Francis J, Oukrif D, Mandair D, Pericleous M, Mohmaduvesh M, et al. Progressive epigenetic dysregulation in neuroendocrine tumour liver metastases. Endocrine-Related Cancer 201724 L21-L25. (https://doi. org/10.1530/ERC-16-0419)

32 Keck KJ, Breheny P, Braun TA, Darbro B, Li G, Dillon JS, Bellizzi AM, O'Dorisio TM \& Howe JR. Changes in gene expression in small bowel neuroendocrine tumors associated with progression to metastases. Surgery 2018163 232-239. (https://doi.org/10.1016/j. surg.2017.07.031)

33 Fotouhi O, Abdel Fahmideh M, Kjellman M, Sulaiman L, Höög A, Zedenius J, Hashemi J \& Larsson C. Global hypomethylation and promoter methylation in small intestinal neuroendocrine tumors. Epigenetics 20149 987-997. (https://doi.org/10.4161/epi.28936)

34 Edfeldt K, Björklund P, Akerstörm G, Westin G, Hellman P \& Stålberg P. Different gene expression profiles in metastasizing midgut carcinoid tumours. Endocrine-Related Cancer 201118 479-489. (https://doi.org/10.1530/ERC-10-0256)

35 Di Domenico A, Wiedmer T, Marinoni I \& Perren A. Genetic and epigenetic drivers of neuroendocrine tumors (NET). Endocrine-Related Cancer 201724 R315-R334. (https://doi.org/10.1530/ERC-17-0012)

36 Dumanski JP, Rasi C, Björklund P, Davies H, Ali AS, Grönberg M, Wellin S, Sorbye H, Grønbæk H, Cunningham JL, et al. A MUTYH germline mutation is associated with small intestinal neuroendocrine tumours. Endocrine-Related Cancer 201724 427-443. (https://doi. org/10.1530/ERC-17-0196)

37 Raj N, Shah R, Stadler Z, Mukherjee S, Chou J, Untch B, Li J, Kelly V, Saltz B, Mandelker D, et al. Real-time genomic characterization of metastatic pancreatic neuroendocrine tumors has prognostic implications and identifies potential germline actionability. JCO Precision Oncology 20182018 1-18. (https://doi.org/10.1200/ PO.17.00267)

38 Holliday R. The inheritance of epigenetic defects. Science 1987238 163-170. (https://doi.org/10.1126/science.3310230)

39 Stålberg P, Westin G \& Thirlwell C. Genetics and epigenetics in small intestinal neuroendocrine tumours. Journal of Internal Medicine 2016 280 584-594. (https://doi.org/10.1111/joim.12526)

40 Ruebel K, Leontovich A, Stilling G, Zhang S, Righi A, Jin L \& Lloyd R. MicroRNA expression in ileal carcinoid tumours: downregulation of microRNA-133a with tumor progression. Modern Pathology 200923 367-375. (https://doi.org/10.1038/modpathol.2009.161)

41 Stricker I, Tzivras D, Nambiar S, Wulf J, Liffers S, Vogt M, Verdoodt B, Tannapfel A \& Mirmohammadsadegh A. Site- and grade-specific diversity of LINE1 methylation pattern in gastroenteropancreatic neuroendocrine tumours. Anticancer Research 201232 3699-3706.

42 Finnerty BM, Gray KD, Moore MD, Zarnegar R, III \& Iii TJF. Epigenetics of gastroenteropancreatic neuroendocrine tumors: https://ec.bioscientifica.com https://doi.org/10.1530/EC-19-0206
(C) 2019 The authors Published by Bioscientifica Ltd

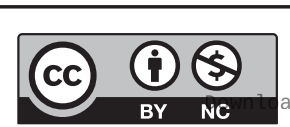

This work is licensed under a Creative Commons Attribution-NonCommercial 4.0 International License. ded from Bioscientifica.com at 04/26/2023 08:28:52AM 
a clinicopathologic perspective. World Journal of Gastrointestinal Oncology 20179 341. (https://doi.org/10.4251/wjgo.v9.i9.341)

43 Choi IS, Estecio MR, Nagano Y, Kim DH, White JA, Yao JC, Issa JP \& Rashid A. Hypomethylation of LINE-1 and Alu in well-differentiated neuroendocrine tumors (pancreatic endocrine tumors and carcinoid tumors). Modern Pathology 200720 802-810. (https://doi. org/10.1038/modpathol.3800825)

44 Zhang H, Rumilla KM, Jin L, Nakamura N, Stilling GA, Ruebel KH, Hobday TJ, Erlichman C, Erickson LA \& Lloyd RV. Association of DNA methylation and epigenetic inactivation of RASSF1A and beta-catenin with metastases in small bowel carcinoid tumors. Endocrine 200630 299-306. (https://doi.org/10.1007/s12020-0060008-1)

45 Bollard J, Massoma P, Vercherat C, Blanc M, Lepinasse F, Gadot N, Couderc C, Poncet G, Walter T, Joly M, et al. The axon guidance molecule semaphorin $3 \mathrm{~F}$ is a negative regulator of tumor progression and proliferation in ileal neuroendocrine tumors. Oncotarget 20156 36731-36745. (https://doi.org/10.18632/oncotarget.5481)

46 Verdugo AD, Crona J, Starker L, Stålberg P, Akerström G, Westin G, Hellman P \& Björklund P. Global DNA methylation patterns through an array-based approach in small intestinal neuroendocrine tumors. Endocrine-Related Cancer 201421 L5-L7. (https://doi.org/10.1530/ ERC-13-0481)

47 Li S, Essaghir A, Martijn C, Lloyd RV, Demoulin J, Öberg K \& Giandomenico V. Global microRNA profiling of well-differentiated small intestinal neuroendocrine tumours. Modern Pathology 201326 685-696. (https://doi.org/10.1038/modpathol.2012.216)

48 Miller HC, Frampton AE, Malczewska A, Ottaviani S, Stronach EA, Flora R, Kaemmerer D, Schwach G, Pfragner R, Faiz O, et al. MicroRNAs associated with small bowel neuroendocrine tumours and their metastases. Endocrine-Related Cancer 201623 711-726. (https://doi.org/10.1530/ERC-16-0044)

49 Georgitsi M, Raitila A, Karhu A, van der Luijt RB, Aalfs CM, Sane T, Vierimma O, Mäkinen MJ, Tuppurainen K, Paschke R, et al. Germline CDKN1B/p27Kip1 mutation in multiple endocrine neoplasia. Journal of Clinical Endocrinology and Metabolism 200792 3321-3325. (https:// doi.org/10.1210/jc.2006-2843)

50 Daskalakis K, Norlén O, Karakatsanis A, Hellman P, Larsson R, Nygern P \& Stålberg P. Ex vivo activity of cytotoxic drugs and targeted agents in small intestinal neuroendocrine tumors. Endocrine-Related Cancer 201825 471-480. (https://doi. org/10.1530/ERC-17-0404)

51 Da Silva A, Bowden M, Zhang S, Masugi Y, Thorner AR, Herbert ZT, Zhou CW, Brais L, Chan JA, Hodi FS, et al. Characterization of the neuroendocrine tumor immune microenvironment. Pancreas 2018 47 1123-1129. (https://doi.org/10.1097/MPA.0000000000001150)

52 Karpathakis A, Dibra H \& Thirwell C. Neuroendocrine tumours: cracking the epigenetic code. Endocrine-Related Cancer 201320 R65-R82. (https://doi.org/10.1530/ERC-12-0338)

53 Ahuja N, Sharma AR \& Baylin SB. Epigenetic therapeutics: a new weapon in the war against cancer. Annual Review of Medicine $2016 \mathbf{6 7}$ 73-89. (https://doi.org/10.1146/annurev-med-111314-035900)

54 Chakraborty C, Sharma AR, Sharma G, Doss CGP \& Lee S. Therapeutic miRNA and siRNA: moving from bench to clinic as next generation medicine. Molecular Therapy: Nucleic Acids 20178 132-143. (https://doi.org/10.1016/j.omtn.2017.06.005)

55 Hanahan D \& Weinberg R. Hallmarks of cancer: the next generation. Cell 2011144 646-674. (https://doi.org/10.1016/j. cell.2011.02.013)

56 Walsh K, Choi M, Oberg K, Kulke M, Yao J, Wu C, Jurkiewicz M, Hsu L, Hooshmand S, Hassan M, et al. A pilot genome-wide association study shows genomic variants enriched in the nontumor cells of patients with well differentiated neuroendocrine tumors of the ileum. Endocrine-Related Cancer 201018 171-180. (https://doi org/10.1677/ERC-10-0248)

57 Norlén O, Edfeldt K, Akerstörm G, Westin G, Hellman P, Björklund P \& Stålberg P. Peritoneal carcinomatosis from small intestinal neuroendocrine tumors: clinical course and genetic profiling. Surgery 2014156 1512-1522. (https://doi.org/10.1016/j. surg.2014.08.090)

Received in final form 21 May 2019

Accepted 10 June 2019

Accepted Preprint published online 10 June 2019 https://ec.bioscientifica.com

https://doi.org/10.1530/EC-19-0206 (c) 2019 The authors Published by Bioscientifica Ltd
This work is licensed under a Creative Commons Attribution-NonCommercial 4.0 International License. ded from Bioscientifica.com at 04/26/2023 08:28:52AM 